\title{
REGRESSÃo COM VARIÁVEIS SUJEITAS A IMPRECISÃO: UMA ABORDAGEM PELO MÉTODO DE MONTE CARLO
}

G. Amaral ${ }^{1}$

\section{RESUMO}

0 presente trabalho propø̃e uma abordagem pelo método de Monte Carlo, para o cálculo de linhas de regressão quando os pontos são afetados por erros ou incertezas. 0 método consiste na definição de um espaço de incerteza para cada ponto, baseada nos erros absolutos en cada dimensão, e amostragem aleatória dentro dele. o conjunto de pontos assim obtidos é utilizado para o cálculo dos paråmetros de regressão, os quais são armazenados pelo programa. Esse procedimento é repetido um número significativo de vezes (tipicamente 1000 ) e, ao final, os resultados armazenados săo descritos estatisticamente. Os resultados assim obtidos foram comparados com aqueles de outros métodos, utilizados rotineiramente para o cálculo de isócronas $\mathrm{Rb} / \mathrm{Sr}$, sem díscrepåncias significativas. As principais vantagens do método ora proposto são sua simplicidade matemática e possibilidade de visualizaçăo e análise estatística dos resultados.

\section{ABSTRACT}

A Monte Carlo approach is presented for the problem of least squares fitting of points with correlated errors. The method consists of the definition of an uncertainity space based on absolute error and random sampling for each data point. This procedure is repeated a large number of times (typically 1000 times) and a regression is obtained for each set of data. The results are stored and described statistically at the end of the process. Comparisons were made with results obtained by conventional methods applled to $\mathrm{Rb} / \mathrm{SI}$ isochrons, without any significant discrepancies. The main advantage of the method now proposed is its simplicity and the possibility of graphical representation of variability.

\section{INTRODUÇĀO}

Um problema ainda năo resolvido de modo satisfatório, é o da obtençăo de coeficientes en modelos de regressão quando as variăveis envolvidas estão sujeitas a imprecisōes. Nestes casos, qualquer que seja o modelo escolhido (duas ou mais variáveis ou grau das funçбes), ao invés de pontos teremos áreas ou volumes e o problema se resumirá em obter uma funçăo que melhor satisfaça essas áreas ou volumes.

Diversos métodos têm sido propostos para esses casos, como por exemplo roRK (1966,

\footnotetext{
Departamento de Metalogênese Geoquímica, Instituto de Geociências/UNICAMP, Campinas, e Depar
} tamento de Paleontologia e Estratigrafia, Instituto de Geociências/USP, Săo Paulo. 
1967 e 1969), MCINTYRE et al. (1966), WILLIAMSON (1968), BROOKS et al. (1972), e outros, para o caso das isócronas Rb/Sr. Tendo trabalhado nesse problema, o autor (AMARAL, 1978) testou uma abordagem pelo método de Monte Carlo, a qual é aqui discutida.

A análise dos trabalhos acima citados, mostra que as abordagens utillzadas são complexas do ponto de vista matemático e geralmente com resultados não muito satisfatórios ou de difícil interpretaçăo. No caso da regressão linear simples, onde temos diversos pares de pontos $\left(x_{1}, y_{1}\right)$ e desejamos os coeficientes de uma função do tipo:

$$
y=a+b x,
$$

- problema resume-se na obtençăo de a e b. No caso particular da isócrona $\mathrm{Rb} / \mathrm{Sr}$, $\mathrm{x}=$ $\mathrm{Rb}^{87} / \mathrm{Sr}^{86}, \quad y=\mathrm{Sr}^{87} / \mathrm{Sr}^{86}, \quad a=\mathrm{R}_{0}$ (razão inicial) e $\mathrm{b}=$ inclinação da reta, proporcional à idade. Como en qualquer regressão, desejamos obter uma estimativa das incertezas em a e b para que possamos utilizar corretamente as razбes iniciais e Idades obtidas. Os métodos propostos anteriormente, nao possibilitam um exame claro das incertezas, o que nos levou a desenvolver uma abordagem do tipo simulaçăo, pelo método de Monte Carlo, o qual é um processo para a resoluçăo de problemas matemáticos através de amostragen aleatóría (SOBO, 1975).

\section{REGRESSÃo PELO MÉTOdO DE MONTE CARLO}

A Idéía básica do método é a obtenção de um número representatívo de regressర̋es, para pontos escolhidos aleatoriamente dentro dos espaços de incerteza. Em outras palavras, no caso da regressão linear, $x_{i} \pm e_{x i}$ e $y_{i} \pm e_{y i}$, definem un retångulo de incerteza para cada ponto de observaçăo ou medída, para cada qual é escolhído um ponto ao acaso e calculada a regressão correspondente. Armazenando-se um núnero significativo de coeficientes (a e b, no caso da regressåo linear simples) e parâmetros de ajuste (coeficiente de determinação e erro padrão), estes podem ser tratados estatisticamente e suas incertezas examinadas de modo mais compreensivel. A Figura 1 esquematiza o procedimento adotado, para una das regressøes.

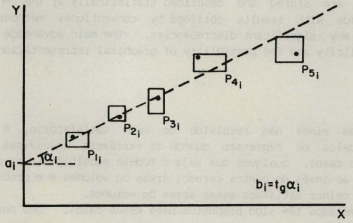

Figura 1 - Esquema de operação do método proposto para uma regressăo. Os retângulos indicam o valor central dos pontos e suas incertezas para $x$ e y. 0 programa, no passo 1 , gera aleatoriamente um ponto dentro de cada ponto $\mathrm{P}_{k}$ e calcula a regressão correspondente, obtendo $a_{i}$ e $b_{i}$ que são armazenados. Após $n$ interaçб̋es o programa calcula os parâmetros estatísticos e desenha os histogramas respectivos. 
De modo a testar o método, desenvolvemos inicialmente um programa en FORTRAN para o sistema Burroughs 6700 da USP, que resultou en nossa primeira comunicação (AMARAL, 1978). Mais recentemente, com a implantação do Laboratório de Informática no Instituto de Geociências da USP, desenvolvemos un novo programa, em BASIC, para mícrocomputadores compativeis com IBMPCXT. 0 algorítmo usado é listado a seguir:

1. Lê $x(i)$, erro de $x(i), y(i)$, erro de $y(i), i=1, n$;

2. selecione a opçăo de regressăo, $x$ en $y, y$ em $x$ ou perpendicular à reta;

3. defina o número de regressőes;

4. o programa define os limites inferior e superior, para $x$ e $y$, de cada ponto de observaçăo (define os retângulos de incerteza);

5. utilizando-se a funçăo de números aleatórios, o programa seleciona um ponto em cada retângulo de incerteza e calcula a regressăo para cada conjunto, armazenando os coeficientes e parâmetros de ajuste encontrados;

6. repetir o passo 5 para o número de regressठ̄es definido em 3 ;

7. descreve estatisticamente os coeficientes e parametros de ajuste, para o conjunto de regressठes efetuadas;

8. imprime os resultados.

o programa acima foil desenvolvido para o caso particular da regressão 1 inear simples. Todavia, com pequenas modificaçరes, ele poderia ser ampliado para outros tipos de regressão. Mais ainda, no caso do presente programa o usuário define os erros em termos absolutos. Caso se disponha de um número significativo de réplicas para cada ponto, os erros poderāo ser tratados em termos de distribuiçס̋es multidimensionais, com esquemas próprios de amostragem aleatória. Nestes casos, ao invés de retångulos, teremos elípses cujos eixos serão proporcionais à variância das incertezas ou flutuaçб̃es aleatórias (BEERS, 1957).

\section{RESULTADOS E DISCUSSĀO}

De modo a testar o método, selecionanos conjuntos de resultados de isócronas Rb-Sr, para os quais são disponivels estimativas das incertezas nos valores $\mathrm{Rb}^{87} / \mathrm{Sr}^{86} \mathrm{e} \mathrm{Sr}^{87} / \mathrm{Sr}^{86}$, como por exemplo aqueles apresentados por AMARAL \& KAWASHITA (1967) para folhelhos do Grupo Bambui na regĩa de Vazante, MG, abaixo listados:

$\begin{array}{rccc}\mathrm{Rb}^{87} / \mathrm{Sr}^{86}(\mathrm{x}) & \text { Incerteza em } x & \mathrm{Sr}^{87} / \mathrm{Sr}^{86}(\mathrm{y}) & \text { Incerteza em y } \\ 22.8 & 1.1 & 1.025 & 0.004 \\ 162.0 & 8.0 & 2.170 & 0.020 \\ 9.3 & 0.5 & 0.876 & 0.010 \\ 60.0 & 3.0 & 1.390 & 0.020 \\ 68.0 & 4.0 & 1.440 & 0.030\end{array}$

Para este conjunto, obtivemos os seguintes resultados:

Intersecçశัo $.8415 \pm .0246$ (2 sigma)

Inclinação .0084t.0004 "

Coeficlente de Correlação .9966士.0026

Idade $589 \pm 40 \mathrm{Ma}(2 \mathrm{sigma}) \quad \lambda=1,42 \cdot 10^{-11}$, ano-1 
De modo a comparar o método aqui proposto com aqueles de YORK (1966 e 1968), WILLIAMSON (1986) e WENOT (In: BROOKS et al., 1972), utilizamo-nos dos dados referentes aos Gnaisses Jeribá, de SIGA Jr. (1968), discutidos em outro trabalho do presente Boletim.

0 procedimento aqui proposto, tanto para regressão y en $x$, como normal à reta, forneceu uma idade de $583+25 \mathrm{Ma}$ ( 2 sigma), com razăo inicial .7188 \pm .0004 (2 sigma). A Tabela I resume as comparações efetuadas entre o método de Monte Carlo e aqueles acima mencionados. A figura 2 mostra os histogramas dos resultados para a intersecçăo (a) e inclinaçăo (b) para 1000 regressర̃es. A distribuição quase normal daqueles valores facilita sua análise estatística:

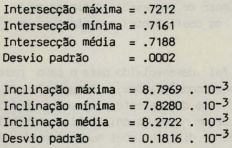

0 exame dos resultados apresentados no parágrafo precedente, permite afirmar que os resultados obtidos com o método ora proposto são aproximadamente coincidentes com aqueles obtidos pelos métodos rotíneiros usados no Centro de Pesquísas Geocronológícas do IG/USP. A principal vantagem do método de Monte Carlo é a sua simplicidade matemática e a possibilidade de visualização das variabilidades sob a forma de histogramas, fatores da maior importância para a correta interpretaçăo dos resultados.

TABELA I

Método

Monte Carlo

York (1966)

Williamson (1968)

York (1968)

Wendt
Idade (Ma) $\quad R_{0}$

$583 \pm 25 \quad .7188 \pm .0004$

$586 \pm 26 \quad .7183 \pm .0010$

$586 \pm 38 \quad .7183 \pm .0028$

$584 \div 42 \quad .7185 \pm .0032$

$584 \pm 36 \quad .7185 \pm .0026$ 


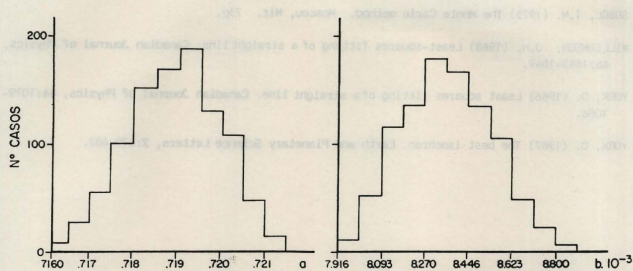

Figura 2 - Histogramas obtidos para a intersecçăo (a) e inclinação (b), no caso dos Gnaisses Jeribá. Foram efetuadas 1000 regressōes. Notar a distribuiçăo claramente normal dos resultados.

\section{CONCLUSĀO}

0 método de regressăo linear pela técnica de amostragem aleatória (Monte Carlo), proposto no presente trabalho, aplicado a dados de isócronas Rb/Sr, forneceu resultados comparáveis aqueles obtidos por outros métodos. A grande vantagem, especialmente para nós que não temos uma profunda formaçăo matemática, é a simplicidade, fator indispensável para a correta interpretaçăo dos resultados.

\section{REFERENCIAS BIBLIOGRAF ICAS}

AMARAL, G. \& KAWASHITA, K. (1967) Determinaçăo da idade do Grupo Bambuí pelo método Rb-Sr. In: CONGRESSO BRASILEIRO DE GEOLOGIA, 21., Curitiba, 1967. Anais. Curitiba, SBG. p.214217 .

AMARAL, G. (1978) Cálculo da isócrona Rb-Sr pelo método de Monte Carlo e significado dos parâmetros estatísticos associados. In: CONGRESSO BRASILEIRO DE GEOLOGIA, 30., Recife, 1978. Boletim de Resumos. Recife, SBG. p.145.

BEERS, Y. (1962) Introduction to the theory of error. Reading, Addison Wesley. $66 p$.

BROOKS, C.; HART, S.R.; WENDT, I. (1972) Reallstic use of two-error regression treatments as applied to rubidium-strontium data. Reviews of Ceophysics and Space Physics, 10(2):551-577.

SIGA Jr., 0. (1986) A evoluçăo geotectônica da porçăo nordeste de Minas Geraís, com base em interpretaçб̄es geocronológicas. Săo Paulo. 140p. (Tese de Mestrado, Instituto de Geociências/USP). 
SOBOL, I.M. (1975) The Monte Carlo method. Moscou, Mir. 73p.

WILLIAMSON, J.H. (1968) Least-squares fitting of a straight line. Canadian Joumal of Physics, 46: $1845-1847$.

YORK, D. (1966) Least squares litting of a straight line. Canadian Journal of Physics, 44:10791086.

YORK, D. (1967) The best isochron. Earth and Planetary Science Letters, 2:479-482. 